\title{
O BRASIL NO FOGO CRUZADO: DOIS ROMANCES SOBRE A SEGUNDA GUERRA MUNDIAL
}

http://dx.doi.org/10.11606/issn.2237-1184.v0i26p12-21

Berta Waldman ${ }^{1}$

Universidade de São Paulo (USP)

RESUMO

PALAVRAS-CHAVE

Este ensaio apresenta uma leitura crítica de Guerra em surdina e Caderno italiano, duas obras de Boris Schnaiderman que contemplam relatos (ficcionais e não-ficcionais) sobre a Segunda Guerra Mundial. Com ênfase no drama histórico e no drama pessoal, expondo conflitos de quem os vivencia e pontos de vista de quem narra, mostra também como a situação da guerra carreou no relato marcas sociais e ideológicas.

\section{ABSTRACT}

This essay presents a critical reading of Guerra em surdina and Caderno italiano, two works written by Boris Schnaiderman dealing with fictional and non-fictional narratives based on the Second World War. Focusing both historical and personal drama the author exposes his own conflicts and shows by different points of view that many of the living situations of the war were responsible for several social and ideological marks involving these two narratives.
Boris

Schnaiderman; drama histórico; drama pessoal; foco narrativo; marcas sociais; marcas ideológicas.

\section{KEYWORDS}

Boris Schnaiderman; historical drama; personal drama; point of view; social and ideological marks.

\footnotetext{
${ }^{1}$ Professora titular do Instituto de Estudos da Linguagem da UNICAMP e professora aposentada do Departamento de Línguas Orientais, onde atuou na área de literatura e cultura hebraica.
} 


\begin{abstract}
"Pense-se na história .que nós mesmos estamos vivendo: quem refletir sobre o procedimento dos indivíduos e dos grupos humanos no nascimento do nacional-socialismo da Alemanha, ou o procedimento dos diférentes povos e Estados antes e durante a atual guerra (1942), sentirá como são dificilmente representáveis os objetos históricos em geral, e como são impróprios para a lenda."
\end{abstract}

Erich Auerbach ${ }^{2}$

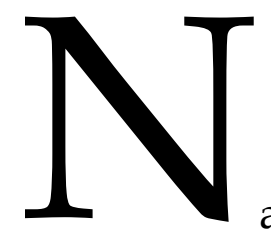

a guerra, o drama histórico e o drama pessoal se cruzam na medida em que os conflitos externos se contraem e se interiorizam, submetidos ao tempo pessoal daquele que os vivencia e os relata. Por sua vez, aquele que vive a situação da guerra carrega boa dose de marcas sociais e ideológicas que apontam tanto para seu país de origem, como para sua classe social. Essa é uma das razões pelas quais um romance, uma novela, um conto, sobre a Segunda Guerra Mundial escrito no Brasil pode apresentar especificidades que os distingue de outros escritos na Europa ou nos Estados Unidos, por exemplo.

A participação do Brasil entre as 16 nações que tomaram parte ativa nos combates contra a Alemanha Nazista (1933-1945) durante a Segunda Guerra Mundial (1939-1945) fez com que a recém constituída Organização das Nações Unidas (1945) ${ }^{3}$ deliberasse por incluí-lo entre os países que deveriam enviar representação ao Conselho Aliado de Controle. Tal órgão era o responsável pela administração do território da Alemanha recém derrotada (18/05/1945).

Entre os combatentes que embarcaram para a Guerra em 2 de julho de 1944, estava o sargento Boris Schnaiderman, nascido na Ucrânia e naturalizado brasileiro. Schnaiderman fez tudo para ser convocado. Filho de imigrantes judeus, pertencente à classe média e formado em Engenharia, a situação política do Brasil não lhe escapa e no seu alvo está o regime autoritário de Getúlio Vargas, que prendia e torturava seus companheiros e precisava ser combatido. Como a militância política no país era perigosa e de alto risco, nosso protagonista considera que a

\footnotetext{
2 Erich Auerbach, Mimesis. 2a ${ }^{\mathrm{a}}$ ed. revista. São Paulo: Perspectiva, p.16.

3 A carta da constituição da ONU foi assinada em 26/07/1945.
} 
participação no conflito poderia suprir a sensação de covardia e aviltamento por estar à margem da ação política nacional. Seu ativismo se viabilizaria a partir de uma convocação para a guerra. Uma vez convocado, o protagonista refletirá sobre as contradições sociais inerentes ao país e seus desdobramentos no plano da guerra.

Para começar, a luta que se empreendia era pela democracia, mas eram os filhos de um país submetido à ditadura que partiam para o combate. Os movimentos estudantis clamavam contra alemães, italianos e japoneses. Mas o ambiente que o protagonista encontra já no quartel e que perdura durante o combate, corrobora o sentimento da maioria da população brasileira que apoiava Getúlio Vargas, creditando o ônus da Guerra a Oswaldo Aranha, considerado americanófilo. Entre o povo simples, predominava um forte sentimento antiamericano e um amor fiel por Vargas, cuja imagem se constrói como uma espécie de "pai do povo". A ironia é que os estudantes que iam às ruas gritar contra a ditadura e pela Guerra permaneceram no país, enquanto os combatentes não tinham nenhuma ideia do que se passava, nem a respeito das forças em combate, nem do espaço geográfico para o qual estavam sendo transferidos.

A participação de Boris Schnaiderman na Força Expedicionária Brasileira originou o romance Guerra em surdina, cuja primeira edição é de 1964.4

Por que o autor optou por escrever ficção e não um depoimento, já que é sua experiência que ocupa o cerne do texto? Escrito muitos anos, após o término da guerra, o autor trabalha com as reminiscências depositadas na memória e as ficcionaliza, em detrimento da opção pelo testemunho. Assim, ele escolhe utilizar práticas enunciativas que lhe permitem transcender o âmbito da experiência pessoal, pois interessam-lhe os aspectos humanos não diluídos na cena pública, que além de trazer à tona diferentes níveis de participação na guerra, revelam também alguns mecanismos que estruturam as relações de classe do Brasil.

Como o texto é um romance, o alter ego do autor, o protagonista João Afonso (às vezes também narrador, em mudanças expressivas do foco narrativo), constata e experimenta, no espaço de tempo em que é convocado e participa do combate na Itália, a apatia e o embrutecimento causados pelo cenário de destruição, morte e fome, além da resistência passiva às ordens que vinham de cima. ${ }^{5}$

Desde o início, é apontada a diferença entre a visão do estudante, que desejara a luta, e a dos homens que se julgavam vendidos aos Estados Unidos pelo governo brasileiro. Porém, enquanto esses homens, sem saber

\footnotetext{
${ }^{4}$ Boris Schnaiderman, Guerra em surdina, 4a. ed. rev. São Paulo: Cosac \& Naify, 2004. Agradeço ao pesquisador e professor Carlos Eduardo Fernandes Netto que me enviou seu trabalho sobre a guerra na ficção brasileira do qual meu texto é, sem dúvida, devedor.

${ }^{5}$ Schnaiderman, 2004, p. 20.
}

14|BORIS SCHNAIDERMAN: Ensaios 
por que nem para que lançavam-se a atos de bravura, João Afonso aproximava-se do ceticismo, mergulhando na incerteza e na falta de perspectiva. Já no navio cinzento que transportava o primeiro contingente de expedicionários, o personagem principal sente $\mathrm{o}$ abalo de suas convicções. O conflito interior revela-se, por exemplo, na seguinte passagem, em que discursos relacionados a experiências diferentes se entrechocam em seu pensamento:

"Sangue, suor e lágrimas", dizia o jornal imbecil. E também: "Viva o Estado Nacional". Estou num mundo louco. Por que eu quero ir para a guerra? Eu devia era ficar lá atrás, que nem os rapazinhos de Copacabana, meus colegas da Faculdade, que a estas horas se espreguiçam na areia da praia. Não, não, o que passou, passou. "Fomos vendidos por dólares." Por que não digo o mesmo? Por que teimei em falar aos meus companheiros sobre o nazismo e a necessidade desta luta? Eles possuem uma lógica inflexível: uns e outros se equivalem, americano e alemão são a mesma coisa, cada um quer tirar as suas vantagens, e o Brasil que se dane, mandando os seus filhos para a guerra, sem ter nada a ver com a história. ${ }^{6}$

De volta ao Brasil, nem o estudante João Afonso, ex-sargento de artilharia, nem os ex-pracinhas, homens do povo, entendem o tratamento de heróis com que são recebidos e aclamados. Permanece insolúvel, para o protagonista, a sensação de que as barreiras ideológicas são intransponíveis. Isolado, seus valores e aspirações não se fundem aos anseios dos demais. Enquanto a entrada em combate era aguardada, ele escreve em seu diário:

A um canto do acampamento, afixa-se diariamente um noticiário muito sucinto dos principais acontecimentos, que passam o mais das vezes quase despercebidos. Fiquei comovido corri a notícia da libertação de Paris, comentei-a com Alípio e poucos mais. Constatei, porém, que a repercussão foi muito pequena entre a tropa. ${ }^{7}$

\footnotetext{
${ }^{6}$ Schnaiderman, 2004, p. 44.

${ }^{7}$ Schnaiderman, 2004, p. 98. A propósito de notícias que chegavam aos combatentes, ver Notícias de uma guerra em edição fac-similar (Léo Christiano Editorial/ RP Consultoria) que reúne os 34 números do jornal "O Cruzeiro do Sul"/Biblioteca do Exército, distribuído aos pracinhas brasileiros na Itália, em 1945. O jornal surgiu no meio militar para levantar o moral da tropa. Esse jornal teve 34 números distribuídos entre 3 de janeiro e 31 de maio de 1945. Circulava apenas entre os combatentes da FEB (Força Expedicionária Brasileira) que lutavam na Itália, no final da Segunda Guerra Mundial. Constam na publicação conselhos de como evitar espiões, atenção com estranhos e com mulheres atraentes sobretudo. Enviavam paisagens do Brasil, fragmentos de crônicas. Alguns nomes que aparecem no jornal e não tinham importância maior na época: "cabo C. Scliar" Carlos Scliar (1920-2001) que se tornaria um artista plástico de grande importância. Há também dois artigos do "soldado Jacó Gorender", mais tarde um destacado historiador marxista do país. O jornalzinho era um lenitivo por transmitir notícias do Brasil.
} 
É de importância fundamental na composição do texto de Boris Schnaiderman a presença do discurso do outro. Por meio desse recurso dialógico, instaura-se o confronto de que provém a tensão semântica da escrita ficcional do autor. O discurso indireto livre torna presente a voz do outro, dando concreção estética ao impasse:

Para minha surpresa, uma notícia que me deixara mais ou menos indiferente fez sensação entre os soldados: Oswaldo Aranha demitira-se do cargo de ministro das Relações Exteriores. Agora sim, dizia-se, a coisa vai melhorar. $\mathrm{O}$ velho vai chamar a gente de volta. Quem nos mandou para cá foi o homem dos americanos, que nos vendeu por uma garrafa de uísque. Agora sim, a guerra vai acabar para nós. Não é à toa que a gente está no estrangeiro faz tanto tempo, e nada de entrar no fogo. Não vê que nem nos ensinaram a atirar direito, todo esse tempo? O velho ficou nos poupando, não deixou que nos pusessem na frigideira de uma vez. Agora, o jeito é tratar de arrumar o saco, que a coisa não demora. Já deve ter navio brasileiro esperando a gente num porto por aí. ${ }^{8}$

Na técnica narrativa empregada, o discurso do outro não se anula nem mesmo quando o autor do diário retoma a palavra, pois não basta, segundo ele pode perceber, descartar a visão divergente e incompreensível, já que não há condições de alterar a situação dominante:

[...] A lenda de um ditador bonzinho, o pai do seu povo, que só deixou enviar os homens para a guerra porque o ministro malvado, vendido aos americanos, obrigara-o a isto, deixa-me profundamente irritado. Mas, sobretudo, estou diante de algo que não compreendo. Não se trata apenas de aceitar ou recusar. Assim como o homem do povo não penetra no meu mundo, historicamente exato, creio eu, onde o ditador aparece com suas características próprias e a ditadura com todo o seu cortejo de infâmias, não posso ter qualquer acesso ao mundo mitológico dos meus patrícios. E a conclusão a que chego é que eu, Alípio e os demais rapazes da mesma condição social, estamos submergidos num mar humano que nos domina e contra o qual é inútil qualquer resistência. O que me resta fazer, sem dúvida, é deixar-me levar pela maré, como fazem Alípio e outros companheiros. ${ }^{9}$

O confronto não ocorre apenas em relação à lógica dos compatriotas, mas também face ao ponto de vista dos soldados americanos. No acampamento estabelecido junto à cidadezinha de Vada, dá-se a troca de experiências e impressões:

Hoje de manhã, fiquei conversando com alguns americanos. Fazem-nos muitas perguntas sobre o Brasil, revelando uma ignorância absurda sobre o assunto. Quando ouviram que viemos de país em regime fascista e que será inevitável uma transformação política em nossa terra, pois é um absurdo lutar pela democracia no estrangeiro e continuar com um regime fascista em casa, responderam mais ou menos assim:

\footnotetext{
${ }^{8}$ Schnaiderman, 2004, p. 98-99.

9 Schnaiderman, 2004, p. 99.
} 
- Então, o que é que vocês pretendem fazer, depois de voltar para casa? Sair às ruas com bandeiras, gritando: "Abaixo a ditadura" e dando tiros em quem continuar pensando que a ditadura não é tão ruim assim? Tudo bobagem. $\mathrm{O}$ homem só tem uma vida para viver e uma pele para defender. Democracia, liberdade, voto secreto, tudo isso é muito bom e bonito mas não compensa uma vida humana que se perde, nem os anos de mocidade gastos na lama e na sujeira.

É frequente perguntarem-nos: "Vocês são todos voluntários?". E, quando se responde negativamente, dizem uns aos outros: "Está vendo? Não são todos trouxas, não".

Este cinismo dos soldados velhos me desagrada profundamente, mas pude percebê-1os em militares de outras nacionalidades também. ${ }^{10}$

O recurso narrativo de apresentar acontecimentos e reflexões por meio de registros em diário busca tornar a voz narrativa, contemporânea aos fatos. No romance Guerra em surdina, as mudanças de foco não acontecem apenas na passagem da primeira para a terceira pessoa, em momentos em que a narração não é feita por João Afonso, mas também na alternância fie perspectivas do mesmo narrador. Assim, o tempo da enunciação que abrange a óptica representada no diário permite enxergar as considerações da voz narrativa, situadas em momentos diferentes, como etapas de um processo inconcluso, configurado esteticamente pela consciência artística ficcional.

(...) Na guerra, eu dormi sobre o mesmo chão com os meus companheiros das mais diversas procedências. Mas agora, há novamente barreiras entre nós. Mantenho contato com Alípio, com Omar e com uns poucos mais. Os outros foram se afastando naturalmente. Então, não adiantou o mergulho de um ano e tanto no mar humano? As pequenas ocupações, a Faculdade, a vida em família, tudo parece cobrir-me novamente com uma crosta e isolar-me do resto. E eu não reajo. Parece que tem de ser assim mesmo. As minhas roupas de paisano, as gravatas coloridas que tive tanto prazer de rever sobre o peito, o teatro que tomei a frequentar (tão difícil acompanhar o enredo!), as pequenas que me telefonam e com quem tomei a sair, meu Deus, meu Deus, será possível que tudo se processe com tamanha rapidez? Há companheiros meus passando fome, sofrendo doença, completamente abandonados depois das caxiadas do regresso. E eu continuo afastado, isolado, arrastando sem nobreza a vida. ${ }^{11}$

$\mathrm{O}$ anseio de compreender os ex-companheiros aflige o estudante João Afonso. Mas os conflitos entre visões de mundo revelam-se insolúveis, por se enraizarem em condições intocadas pela vitória na

10 Schnaiderman, 2004, p. 96.

11 Schnaiderman, 2004, p. 243.

17|BORIS SCHNAIDERMAN: Ensaios 
guerra. Há uma outra guerra preexistente àquela de que participaram em solo italiano. Guerra que se trava "em surdina", mesmo em períodos de paz - "paz em surdina", conforme propõe o título do último capítulo do romance: "E a paz? Também em surdina?". Essas perguntas levam a pensar sobre o que se chama habitualmente de paz, enquanto persistem barreiras que impedem a compreensão recíproca.

Outro dia, tive um exemplo flagrante da distância que tornou a separar-nos. O ditador fora deposto, e, de manhã, quando saí à rua, vi tanques, caminhões com soldados, metralhadoras assestadas, canhões. Fiquei perambulando de propósito pela cidade. Os jornais exultavam, os meus colegas da Faculdade queriam soltar foguetes, mas eu vi os homens do povo sombrios, sem um gesto, sem uma palavra. Passavam pelos canhões, pelas metralhadoras, arredavam-se, mas tudo em silêncio.

O que sabemos nós dos seus mitos e esperanças, da sua sabedoria coletiva e da sua ignorância em relação ao nosso mundo? Como é possível vivermos tão próximos e tão separados? 12

Encerra o livro a pergunta reveladora do caráter inconcluso da busca de conhecimento proposta como desafio ao leitor inserido em uma sociedade cujas estruturas se fundam na desigualdade: "Patrício, com quem convivi um ano e pico, e que continuo a desconhecer, quem és afinal?"13

No livro de Schnaiderman, os quadros descritivos de personagens tomam concretos os sujeitos, cujos modos de ser e de pensar o narrador, sempre atento, anseia compreender. Se, por um lado, o autor não se preocupa em esgotar o relato da guerra, por outro, seu olhar quebra os automatismos que presidem as interações cotidianas entre sujeitos e grupos sociais, armando, assim, um relato de guerra difuso que inclui não apenas as partes em conflito e o conflito propriamente dito, mas também e principalmente os agentes da guerra em sua espessura humana e social. Para se fazer um balanço do que entra na seleção do autor, é fundamental entender que $\mathrm{o}$ ato de seleção trabalha, ao mesmo tempo, contra a referencial idade automática, assim como oferece uma referência seletiva. Da tela de referência seletiva que o romance de Schnaiderman constrói, fica fora o aspecto mais terrível da Segunda Guerra que é justamente o grau de corrosão e destruição do Nazismo. Hitler não é mencionado, nem são mencionados os judeus e outras minorias vítimas do extermínio nazista. Como o romance foi publicado em 1964, esses dados já eram amplamente conhecidos, mas foram lançados intencionalmente fora do foco de visão do autor voltado à visão diz combatente brasileiro e à sua própria posição na

12 Schnaiderman, 2004, p. 246.

${ }^{13}$ Schnaiderman, 2004, p. 246.

18|B ORIS SCHNAIDERMAN: Ensaios 
guerra, com toda a gama de questões que as duas inserções trazem a reboque.

\section{Caderno Italiano, uma correção de rota?}

Reescrever um livro e publicá-lo duas vezes é uma ocorrência rara na História da Literatura. No caso em questão, trata-se de dois livros com o mesmo objetivo, mas o relato resulta diverso. Isto ocorre com Boris Schnaiderman que apresenta sua experiência de participação na FEB (Força Expedicionária Brasileira), durante a II Guerra Mundial, em forma de ficção, terceira pessoa, em Guerra em Surdina 14 e, muitos anos depois, em primeira pessoa, no recém publicado Caderno Italiano (São Paulo: Perspectiva, 2015).

A mudança de foco carreia consequências importantes, pois são postas de lado as máscaras, e o objeto do relato é encarado sem subterfúgios, num texto que releva a experiência e o sujeito da experiência, aproximando, consequentemente, o leitor do acontecido, ao mesmo tempo que amplia a credibilidade do narrador/autor. Afinal, é ele, em primeiro plano que passa a contar seu envolvimento no conflito. A guerra aconteceu, o Brasil participou dela e Boris Schnaiderman foi um dos pracinhas enviados para lutar na Itália. Mas, o que move o autor a retomar a mesma experiência em chave diversa?

Com certeza, sua intenção foi a de ressaltar o lastro da experiência vivida através de um olhar direto e, assim, aproximar o leitor do acontecido, com o ganho em credibilidade alcançado graças à utilização da primeira pessoa, capaz de recuperar uma vivência, sem subterfúgios. $O$ sentimento de insatisfação em relação ao relato romanceado, a eleição de um olhar que aponta direto ao que interessa, não deixa de ser uma correção de rota, embora o modo-como esse sujeito se apresenta seja complexo por natureza.

Formado em Agronomia, atuou durante muitos anos como professor de literatura russa na Universidade de São Paulo; tradutor de destaque, introduziu no Brasil poetas e prosadores russos da maior importância, além de ter fundado a área de russo, na Universidade de São Paulo (USP), que é hoje parte do departamento de Letras Orientais; atuante em diferentes campos do conhecimento, Boris Schnaiderman é um estudioso polimorfo: "agrônomo do asfalto", de "livrarias", atento às artes em geral e à literatura em particular; "um pacifista no front", que, ao contrário dos que fugiam da guerra, fez um esforço para dela participar . Foi com júbilo que, numa manhã de 1944, leu seu nome na relação dos pracinhas convocados. Nessa data, o Holocausto dos judeus ainda era

${ }^{14}$ B, Schnaiderman, Guerra em Surdina. São Paulo: Cosac Naify, 2004.

19|BORIS SCHNAIDERMAN: Ensaios 
camuflado; a posição do Brasil no combate era ambígua e abria brecha para a adesão do país às forças fascistas, conforme se podia depreender dos discursos de Getúlio Vargas. A decepção com o comunismo depois que a Alemanha e a União Soviética assinaram um pacto de não-agressão, em 1939, abate o autor. Pouco depois, os alemães invadiram a Polônia, dando início à Segunda Guerra. Boris Schnaiderman passou mais de um ano na Itália (entre 1944 e1945), atuando como calculador de tiro de artilharia. Ele participou do ataque ao Monte Castello (norte da Itália), a mais simbólica batalha brasileira na guerra; após algumas derrotas, os brasileiros venceram a resistência alemã e conquistaram o Monte em fevereiro de 1945. A vitória foi unia surpresa para o autor, que conta, no livro, ter permanecido mais de 48 horas ininterruptas fazendo cálculo de tiro, na ocasião.

A decepção, o choque de realidade que Boris Schnaiderman vai apresentando ao leitor em diferentes momentos da guerra, são marcantes. Ele se refere, por exemplo, a episódios que esbarram na ação conjunta entre soviéticos e nazistas. É o caso da partilha da Polônia entre os dois gtupos, no início da II Guerra Mundial. Após muitos anos é que foi possível medir a amplitude do massacre de Katyn, com a eliminação dos oficiais do exército polonês, aprisionados pelos russos, num total de milhares ${ }^{15}$. Outro episódio chocante foi a ocupação da,Noruega pelos nazistas, quando o autor soube que Knut Hamsun havia manifestado seu apoio aos invasores e ao governo fantoche de Quisling, pois Fome, obra do escritor norueguês, era um dos livros de cabeceira de Schnaiderman; ${ }^{16}$ não fazia sentido que a obra que ele lia como sendo de protesto, tivesse seu autor do lado dos nazistas. Também Tchékhov, lembra Schnaiderman, tinha manifestado seu entusiasmo pelo autor, numa época em que era mal conhecido até em sua pátria e, numa carta ao romancista norueguês, Górki escrevia: "Digo-lhe com toda a sinceridade, o senhor é o maior artista da Europa, não existe em nenhum país alguém que seja seu igual."17

São contagiantes e plenos de sensibilidade os momentos protagonizados pelo povo brasileiro, recordados por Schnaiderman. Encostado na amurada do navio, o autor observa um grupo formado na proa. Um conjunto de mulatos de morro carioca empunhava seus violões Com jeito profissional. Eles entoaram um samba de Herivelto Martins:

"Odete ouve o meu lamento; lamento de um coração magoado..."

\footnotetext{
${ }^{15}$ Ver página 156 de Caderno Italiano . 5.Pauio, Perspectiva, 2015.

16 Ver página 156 de Caderno Italiano, id. Ibid.

17 Ver página 157.

20|BORIS SCHNAIDERMAN: Ensaios
} 
O que terá acontecido com eles? Terão sobrevivido às investidas insanas contra os alemães de Monte Castelo? A nota de tristeza que vem da música contamina o autor que demonstra uma admiração-p.mfunda pelo homem do povo, que entoa seu canto em momentos sempre oportunos.

Outra lembrança que merece destaque diz respeito à identificação do soldado da FEB com a população civil numa hora do rancho. $\mathrm{O}$ caldeirão fumegante à sombra de uma árvore, uma fila de praças de marmita na mão, e, do outro lado, uma população miserável, que incluía crianças maltrapilhas, com os olhos acesos dirigidos para o caldeirão. Os soldados enchiam a marmita e a entregavam aos populares que assistiam à cena.

Em seguida, o autor lembra-se do filme dirigido por Roberto Rosselini, Roma, Cidade Aberta, que deixa nele profunda impressão. Mas o irmão de seu pai, o tio Isaac, faz um comentário desfavorável do mesmo filme: "certamente, ele exagera, é uma fantasia, eu não acredito na tão apregoada resistência dos italianos ao fascismo."

Apesar de Schnaiderman ter visto os partisanos lutando do seu lado, ouviu o tio dizer o contrário e sabia que não adiantava replicar. Afinal, qual o limite entre fato histórico e ficção? Não será essa a questão que subjaz nas duas versões sobre a II Guerra elaboradas por Boris Schnaiderman? 